\title{
DEVELOPMENT OF PERFORMANCE ASSESSMENT INSTRUMENT FOR NURSES BASED ON WEB IN INPATIENT UNIT
}

\author{
Aprilia Nuryanti, Nursalam, Mira Triharini \\ Master Program of Nursing, Faculty of Nursing, Universitas Airlangga \\ Email: aprilnuryanti@gmail.com
}

\begin{abstract}
Introduction: Performance assessment instrument will be problematic when it is not representative in describing the competency because it is not obvious indicators and inappropriate performance standard to nursing's task. The purpose of this study is to develop nurses' performance assessment instrument based on the web from multi sources assessment inpatient unit at SMC Hospital. Methods: This study had two phases. The first phase was an explanatory overview of the performance assessment system using questionnaires completed by 53 respondents of nurses, selected by purposive sampling. Instrument development based on FGD with six decision makers in the hospital. Validity was tested by Pearson Product Moment Correlation and reliability of instrument's was tested by alpha Cronbach. The second phase was socialization and instrument test to observe the quality of instrument using a questionnaire by 47 respondents and recommendations made by 8 participants of FGD. The samples were selected by purposive sampling technique. Performance assessment system was moderate at $58.49 \%$. All questions which aimed to measure the performance of nurses were valid and reliable. The quality of nurses' performance assessment instruments based on the web was a good category, which was functionality: 81.60 ; reliability: 78.16 ; efficiency: 80.85 ; usability: 81.70 and portability: 81.70 . Results: The result was a web-based assessment format, scoring with Likert scale, resource assessment by the direct supervisor which was a multisource evaluator, the development of performance graph, and confidentiality of data on the database server. Discussion: Recommendations for hospital is to make policy based on the final value of the performance assessment by the supervisor which was multisource feedback and it needs a global writing on a form of performance assessment result.
\end{abstract}

Keywords: assessment instrument, nurses' performance, web

\section{INTRODUCTION}

Performance measurement is an important thing for the development of the health care system (Beyan \& Baykal 2012). Performance assessment instrument will be a problem if it does not describe competencies (Kalb et al. 2006) and inappropriate performance standard to the nurses' task (Nikpeyma et al. 2014). Satisfaction of the performance assessment which is done by managers influences positive things to build and improve performance, if the employees are not satisfied and feel the unfair process, they are unlikely to receive and utilize the assessment (Keeping \& Levy 2000; Giles \& Mossholder 1990 cit. Dusterhoff et al. 2013).

Basic competency assessments for nurses at Samarinda Medika Citra hospital had the same characteristics with the assessment for the whole employees. The nurse's performance assessment was conducted by self-assessment - supervisor evaluation (SAPA). Indicator assessment was in accordance with nursing profession, and the development of assessor resources have been expected to increase the satisfaction of the assessment process and the results of the assessment utilized. The purpose of this study is to develop nurses' performance assessment instrument with web-based in the inpatient unit of Samarinda Medika Citra Hospital.

The performance assessment will not increase productivity if there are biased, inaccurate and not accepted by users due to errors in the content evaluation, which are bias in the evaluation process, incompatibility between the needs of employees and the purpose of the assessment or there is not clear performance dimensions (Giangreco, et al. 2012 cit. Nikpeyma et al. 2014). Less objective assessment leads to a subjective value. Assessment which is not objective, unfair or unreliable (called bias such as Hallo effect, leniency or strictness, central tendencies, Matthew effect and the supervisor 's bias) causes distortion of the assessment process and will also be a source of frustration for employees who are discriminated (Nikpeyma et al. 2014).

Multisource assessment is proven as an alternative to conventional valuation methods to increase employee's satisfaction ratings (Manoharan et al. 2012). Development of information technology and communication may cause nurses to have a computer-based management information system to support decision-making. Data processing with computer assessment is easier, faster, more reliable and more organized to avoid human 
error manually. People nowadays use the internet to obtain information, it is supported by the development of mobile devices such as tablets and smartphones which make people easier to perform Web-based activities (Richwandi 2015).

The concept of nurse performance assessment instrument using an approach is carried out by several sources. The assessment using the web aims to protect confidentiality and accessed restrictions reports. Graph of performance assessment is expected to map out the nurse work performance. The performance indicators in this research are developed with basic competencies (behaviors work and personal character) stated in Government Regulation Number 46 of 2011, and professional performance standard of nurses in the patient satisfaction views according to Nursalam (2014). Instrument's quality will be assessed by software standards of ISO 9126. Validity and reliability of the instrument are tested before it was put in the web application.

\section{MATERIALS AND METHODS}

This research design was an explanative survey to describe nurses' performance assessment and construct a development of performance instrument used with Focus
Group Discussion (FGD). Validity was tested by Pearson Product Moment Correlation and reliability was tested by Alpha Cronbach. The second round was socialization, mentoring, and testing of the instrument by the user from the administrator, head of nurses, nurses, and patients. The final result of the instrument testing was evaluation instrument quality and recommendation based on the evaluation.

Sample and participant were selected by purposive sampling technique. The first round of this study was selected 53 samples and 6 respondents for discussion. The second round was 47 samples and six respondents for discussion.

\section{RESULTS}

Evaluation of the nurse performance assessment system was conducted by using a questionnaire to 53 sample of nurses in child care unit, maternal care unit, ICU, NICU/ PICU, a maternity room, surgery room and newborn nursery unit. Thirty-one nurses $(58.49 \%)$ found had moderate performance, 20 nurses $(37.74 \%)$ had good performance and 2 nurses $(3.77 \%)$ still had poor performance in doing an assessment to patients. The component of the assessment performance described in Table 1.

Table 1. Evaluation of The Nurses' Performance Assessment Component in inpatient unit at Samarinda Medika Citra hospital (N=53)

\begin{tabular}{|c|c|c|c|c|c|}
\hline \multirow[t]{2}{*}{ No } & \multirow{2}{*}{ Component } & \multicolumn{4}{|c|}{ Categories } \\
\hline & & $\begin{array}{l}\text { Good } \\
\mathrm{f}(\%)\end{array}$ & $\begin{array}{c}\text { Moderate } \\
\mathrm{f}(\%)\end{array}$ & $\begin{array}{l}\text { Poor } \\
\mathrm{f}(\%)\end{array}$ & $\begin{array}{l}\text { Total } \\
\mathrm{f}(\%)\end{array}$ \\
\hline 1 & Evaluation Criteria & $37(69,81)$ & $6(11,32)$ & $10(18,87)$ & $53(100)$ \\
\hline 2 & $\begin{array}{l}\text { Value of Performance } \\
\text { Measurement }\end{array}$ & $44(83,02)$ & $7(13,21)$ & $2(3,77)$ & $53(100)$ \\
\hline 3 & $\begin{array}{l}\text { Performance assessment } \\
\text { system }\end{array}$ & $35(66,04)$ & $12(22,64)$ & $6(11,32)$ & $53(100)$ \\
\hline 4 & Assessment feedback & $36(67,92)$ & $11(20,75)$ & $6(11,32)$ & $53(100)$ \\
\hline 5 & Performance report & $30(56,60)$ & $22(41,51)$ & $1(1,89)$ & $53(100)$ \\
\hline 6 & $\begin{array}{l}\text { Performance achievement } \\
\text { determination }\end{array}$ & $25(47,17)$ & $17(32,08)$ & $11(20,75)$ & $53(100)$ \\
\hline 7 & Assessor objectivity & $34(64,15)$ & $19(35,85)$ & $0(0)$ & $53(100)$ \\
\hline 8 & $\begin{array}{l}\text { Satisfaction of performance } \\
\text { assessment system }\end{array}$ & $46(86,79)$ & $6(11,32)$ & $1(1,89)$ & $53(100)$ \\
\hline 9 & $\begin{array}{l}\text { Satisfaction of supervisor's } \\
\text { evaluation }\end{array}$ & $37(69,81)$ & $15(28,30)$ & $1(1,89)$ & $53(100)$ \\
\hline 10 & $\begin{array}{l}\text { Supervisor's knowledge for } \\
\text { true performance }\end{array}$ & $31(58,49)$ & $20(37,74)$ & $2(3,77)$ & $53(100)$ \\
\hline 11 & Satisfaction of feedback & $27(50,95)$ & $15(28,30)$ & $11(20,75)$ & $53(100)$ \\
\hline
\end{tabular}


Table 2. Quality Value of Nurses Performance Assessment Instrument based on the web (N=47)

\begin{tabular}{llcccc}
\hline No & Component & \multicolumn{3}{c}{ Categories } & $\begin{array}{c}\text { Total } \\
\mathrm{f}(\%)\end{array}$ \\
\cline { 3 - 5 } & & $\begin{array}{c}\text { Good } \\
\mathrm{f}(\%)\end{array}$ & $\begin{array}{c}\text { Moderate } \\
\mathrm{f}(\%)\end{array}$ & $\begin{array}{c}\text { Poor } \\
\mathrm{f}(\%)\end{array}$ & \\
\hline 1 & Functionality & $38(80,85)$ & $9(19,15)$ & 0 & $47(100)$ \\
2 & Realiability & $30(63,83)$ & $17(36,17)$ & 0 & $47(100)$ \\
3 & Usability & $35(74,47)$ & $12(25,53)$ & 0 & $47(100)$ \\
4 & Efficiency & $33(70,21)$ & $14(29,79)$ & 0 & $47(100)$ \\
5 & Portability & $34(72,34)$ & $13(27,66)$ & 0 & $47(100)$ \\
\hline
\end{tabular}

Focus group discussion was conducted by the policy makers to discuss the issue and make recommendations for the development of the instrument. Validity and reliability's instrument content tested, either the institution evaluation or the patient assessment, showed valid and reliable for all questions.

In the second round, socialization and mentoring during instrument testing in the adult patient unit 1,2 and 3, conducted by the researcher to help user system, provide manual book user for the instrument based on the web, provide contact number which can be reached anytime if facing obstacles. During the trial, if an error occurred, the researcher would communicate to the web developer for instrument recovering.

The instrument was applied to 47 users (1 administrator, 3 nurse unit managers, 29 nurses and 14 patients). The result for all quality indicators was good with the functionality (81.60); reliability (78.16); efficiency (80.85); usability (81.70), and portability (81.70). FGD conducted by users did observe the evaluation during the instrument trial and made recommendations for its further development.

The development of nurses performance assessment instrument was basic competencies assessment indicator. The scoring system was originally used 1a, 1b, 2a, 2b, 3a, 3b, 4a and $4 b$ (score 1-8) with a maximum value of the acquisition of 8 , while the development of instrument using a Likert scale with scoring (1-5) according to the indicator denominator. SA-PA assessor source was developed with peer and patient assessment rating. The database was provided safely on the server. The web-based instrument could be modified according to hospital needs.

\section{DISCUSSION}

The majority of evaluation of the performance assessment system was a moderate category. The most contributing proportion of satisfaction with the system was good. The source of the assessment methods was self-assessment supervisor (SA-PA). Performance evaluation practices have a positive influence on employee performance (Gyensare \& Asare 2012).

Development of instruments in this study was the structure of the instrument and the content of the assessment criteria. One of the main parts of the implementation was performance measurement. It was influenced by factors such as perspective assessment of decision makers, data source, the focus of measurement, the achievement of development targets, types of indicator, data and investigation types. Performance assessment using this web allows structures to start measurement and qualitative types of indicator that provide a view of the professional behavior performance of nurses, the development of each work behavior assessment indicator can be used as a material for the supervisor to supervise its nurse subordinates. The data type uses a Likert scale (1-5), which allows comparing the measurement values with the numerator and denominator defined. Three of the eight stages performance assessment according to Olabode et al. (2013) can be provided by a web-based performance assessment instruments: 1) Ratings. This stage involves documenting the performance by observing, reminding, evaluating, communicating, assessment and analysis of data. This stage is putting together a record of votes. The information technologybased applications usage enables the acceleration of the conventional paper-based assessment and mathematical calculation performance score manually; 2) Feedback. After the stage of formal assessment, feedback sessions is done as willingness. This session should involve verbal communication, listening, problem-solving, negotiation, 
compromising, conflict resolution, and agreement; 3) Decision-making. Results of the assessment and feedback will lead many decisions made for example of the award (promotions, incentives, etc.) and penalties (e.g., demotion).

Web quality assessment instruments indicators are functionality, reliability, efficiency, usability, and portability. Good was the highest percentages of functionality (web capability assessment of performance in meeting user needs in its function to measure the performance of nurses). The concept of the instrument characteristics was in accordance with the characteristics of software quality by ISO 9126 (International Organization for Standardization), in this study are based assessment from the point of view (user's view). Functionality is the ability to provide the satisfaction of user needs. Reliability is the ability of the software to treat level of performance. Usability is the ability associated with the use of the software. Efficiency is the ability associated with physical resources that are used when the software is run. Portability is the ability associated with software capabilities that are sent to different environments. An instrument is a tool or a means by which to measure the level of scientific work, official documents and legal form, can be used for research tools and results of data collection used as an ingredient in achieving objectives or specific policy.

\section{CONCLUSIONS}

The conclusion of this study 1) Nurses performance assessment system in SMC hospital was in enough category, poor category was the most dominating proportion for job awarding and satisfaction determination of the assessment; 2) FGD recommendation is to develop assessor source with peer and patient assessment, and also assessment type consists of checklist, recording, and note assessment, time assessment, specific indicator assessment for nurse task and questionnaire for assessment. Nurse achievement started from getting scores in 80 for final score of performance, needing essay column to complete the assessment, legalization for the recording assessment and security assessment process in the instrument based on the web which is the regulation needed; 3) All of the question for assessor from head, peer and patients were valid and reliable; 4) Socialization and mentoring to users of instrument was based on the web during trial and there was manual book for application users; 5) Nurse performance assessment instrument was based on web assessed by all user levels (admin, head of the nurse, nurses, and patients), they showed good category for all indicators (functionality, reliability, efficiency, usability dan portability) 6) FGD with users made recommendations that needed socialization and training performance assessment instrument user who was specifically set by hospital, the registration should be done independently by entering nurse's email which managed by administrator. In developing the content of assessment indicators, they did similar additional indicators with technical competence assessment.

Recommendations of this study for the hospital is to invest in IT engineering, and also it should involve another profession (doctor, physiotherapist, nutritionist, etc.) as an assessor, makes policies about the final score of nurse assessment from multi-sources and increase internet network bandwidth in the hospital. For managers and nursing committee, they should formulate a fair scoring in the assessment of the nurse's performance. For the head nurse, they should continue motivating nurses in using the web to provide its assessment evaluation instrument for the next development. For further research should develop the web with quantitative indicators for nurses assessment.

\section{REFERENCES}

Beyan, O.D. \& Baykal, N., 2012. A knowledge based search tool for performance measures in health care systems. Journal of medical systems, 36(1), pp.201-21.

Dusterhoff, C., Cunningham, J.B. \& MacGregor, J.N., 2013. The Effects of Performance Rating, Leader-Member Exchange, Perceived Utility, and Organizational Justice on Performance Appraisal Satisfaction: Applying a Moral Judgment Perspective. Journal of Business Ethics, pp.1-9.

Gyensare, M.A. \& Asare, J., 2012. Relationship between human resource ( HR ) practices and perceived 
Development of Performance Assessment Instrument (Aprilia Nuryanti et.al)

performance of psychiatry nurses in Ghana. African Journal of Business Management, 6(6), pp.2137-2142.

Kalb, K.B. et al., 2006. A competency-based approach to public health nursing performance appraisal. Public Health Nursing, 23(2), pp.115-138.

Manoharan, T.R., Muralidharan, C. \& DeshmukDh, S.G., 2012. A composite model for employees' performance appraisal and improvement. European Journal of Training and Development, 36(4), pp.448-480.

Nikpeyma, N. et al., 2014. Problems of Clinical Nurse Performance Appraisal
System: A Qualitative Study. Asian Nursing Research, 8(1), pp.15-22.

Olabode, T., Abayomi, A. \& Abayomi, A., 2013. Appraisal system: A tool for performance in selected organizations in Nigeria. International Journal of Sociology and Anthropology, 5(7), pp.249-261.

Richwandi, P.P., 2015. PENGGUNAAN HTML5 DALAM PERKEMBANGAN WEB 2 . 0 YANG DIRANCANG DENGAN RESPONSIVE WEB DESIGN. Jurnal Teknik Informatika, Juni, pp.1-10. 